\title{
Improving the quality of coal is one of the factors in intensification of combustion processes in coal-based energy
}

\author{
Yuriy Patrakov ${ }^{1}$, Svetlana Semenova ${ }^{1}$, and Anna Usanina $^{1,2^{*}}$ \\ ${ }^{1}$ The Federal Research Center of Coal and Coal Chemistry of SB RAS, 650000 Kemerovo, Russia \\ ${ }^{2}$ Tomsk State University, 634050 Tomsk, Russia
}

\begin{abstract}
For flotation enrichment of coals, spent engine oils modified with ozone were used. Preliminary ozonation contributes to the increase in the share of low-boiling components in the compositions of spent oils, also it reduces the viscosity of reagents and improves their flotation properties when coals are enriched. By flotation of coal, using ozonized spent oils, the yield of concentrate significantly increases, ash content is reduced, mineralization of waste flotation is increased, and as a result, the selectivity of the process is increased as well.
\end{abstract}

\section{Introduction}

The high ash content of ordinary energy coals significantly reduces the caloric content of fuel, increases the cost of energy produced, and also causes difficulties in the operation of boiler equipment. Therefore, one of the strategies in the coal industry development is the widespread introduction of enrichment technologies for energy coals in order to obtain high-calorie fuel.

The development of highly mechanized methods of production entails the formation of large quantities of fine coal with particle size $<0.1 \mathrm{~mm}$. Nowadays, the only effective way of enriching the thin sludge is froth flotation, which is based on the difference of physicochemical properties (wettability) in the surface and in the particles of coal and rock.

To improve flotation properties of coal particles, surfactants is flotation reagents are used, which are divided into collectors and blowing agents. Petrochemical products and wastes are mainly used in the flotation enrichment of coal. Non-polar reagents are employed as collectors: diesel fuel, kerosene, gas oil, airplane fuel, and mineral oil. Heteropolar reagents are employed as frothing agents, for example, waste of recycling technical alcohols [1]. For the solution of ecological problems, (as flotation reagents) it is offered to use the spent motor oils which are formed in huge quantities, including operation of motor transport of the mining enterprises.

To obtain reagents with both frothing and collection properties, the traditional non-polar flotation reagents are modified by chemical or physicochemical means. For more effective

\footnotetext{
* Corresponding author: usaninaanna@mail.ru
} 
flotation, the reagent must have a polar heteroatom $(\mathrm{O}, \mathrm{S}, \mathrm{N})$ or a functional group $(\mathrm{OH}$, $\mathrm{C}=\mathrm{O}, \mathrm{N}-\mathrm{H}, \mathrm{S}-\mathrm{H}$, etc.) [2].

Ozonization is an effective method of oxidative modification. Some advantages of ozone over the traditional oxidants are used in chemistry and chemical technology (mineral acids, hydrogen peroxide, potassium permanganate, molecular, oxygen, etc.). They are as follows: low reactivity; selectivity for specific types of bonds and heteroatoms; mild oxidation conditions (with no need for catalysts, high temperatures or high pressure); and no byproducts to remove, with a corresponding reduction in production costs [3].

The aim of this work is to investigate the influence of ozonization on the composition of the spent motor oil so as to improve its flotation properties in coal enrichment.

\section{Experimental setup and study technique}

As the object of the study spent mineral oil was used, which were collected from coal mines in Kuzbass, where heavy trucks are operated. The characteristics of the spent motor oil are: density (at $20{ }^{\circ} \mathrm{C}$ ) $874 \mathrm{~kg} / \mathrm{m}^{3}$; kinematic viscosity (at $50{ }^{\circ} \mathrm{C}$ ) $41.2 \mathrm{sSt}$; moisture content $1.5 \%$; ash content $1.2 \%$; mechanical impurities $1.0 \%$.

A bubbling reactor was used for the spent motor oil ozonization in condition of room temperature and atmospheric pressure. The ozone concentrations at the reactor input and output were determined by UV gas analysis (on the basis of the UV absorption of ozone at a wavelength of $254 \mathrm{~nm}$ ).

A laboratory flotation machine (volume $1 \mathrm{~L}$ ) was employed. The experimental results were assessed in terms of the yield of concentrate and the yield of wastes, the ash content of the concentrate and the wastes, and the selectivity of the process.

\section{Experimental results}

The spent oils have been tested for flotation of coals of different grades, different stages of metamorphism and petrographic composition, which can potentially be used as energy coals (Table 1). The table shows the parameters of coal quality: $A^{d}-$ ash, $V^{d a f}-$ yield of volatile substances, $y$ - thickness of the plastic layer, $R_{o}$ - reflection index of vitrinite, $V t-$ vitrinite, $S v$ - semivitrinite, $I$ - inertinite, $L$ - liptinite.

Table 1. Parameters of coal samples.

\begin{tabular}{|c|c|c|c|c|c|c|c|c|c|}
\hline \multirow{2}{*}{$\begin{array}{c}\text { Sample } \\
\text { code }\end{array}$} & \multirow{2}{*}{ Coal } & \multirow{2}{*}{$\begin{array}{l}A^{d}, \\
\%\end{array}$} & \multirow{2}{*}{$\begin{array}{c}V^{d a f}, \\
\%\end{array}$} & \multirow{2}{*}{$\begin{array}{c}y, \\
\mathbf{m m}\end{array}$} & \multirow{2}{*}{$\begin{array}{c}R_{o}, \\
\%\end{array}$} & \multicolumn{4}{|c|}{ Maceral composition, $\%$} \\
\hline & & & & & & $V t$ & $S v$ & $I$ & $L$ \\
\hline 1 & Sibir'coal & 20.4 & 38.1 & 17 & 0.81 & 85 & 2 & 11 & 2 \\
\hline 2 & Krasnobrodskaya coal & 8.5 & 26.5 & 10 & 1.07 & 47 & 10 & 42 & 1 \\
\hline 3 & Tomusinskaya coal & 15.6 & 23.3 & 13 & 1.25 & 50 & 19 & 30 & 1 \\
\hline 4 & Anzherskaya coal & 16.5 & 19.3 & 10 & 1.32 & 49 & 5 & 45 & 1 \\
\hline
\end{tabular}

The success of flotation largely depends on the molecular structure of coals and the presence of functional oxygen-containing groups on the surface of coal particles [4]. For example, low-metamorphosed coals have increased amounts of hydrophilic carboxyl and hydroxyl groups. This has a negative impact on the efficiency of flotation and requires increased costs of hydrophobizing reagents. Coals of medium and high stages of metamorphism consist mainly of hydrophobic hydrocarbon aliphatic-aromatic fragments which are similar to oil-based reagents [5]. Characteristics of the investigated coals are shown in Table 2. 
Table 2. Chemical composition of coal samples.

\begin{tabular}{|c|c|c|c|c|c|c|c|c|c|c|}
\hline \multirow{2}{*}{$\begin{array}{c}\text { Sample } \\
\text { code }\end{array}$} & \multicolumn{4}{|c|}{ Content, \% (daf) } & \multicolumn{3}{c|}{ Atomic ratio } & \multicolumn{3}{c|}{$\begin{array}{c}\text { Functional composition, } \\
\text { mg-equ/g }\end{array}$} \\
\cline { 2 - 12 } & $\mathbf{C}$ & $\mathbf{H}$ & $\mathbf{N}$ & $\boldsymbol{S}$ & $\mathbf{O}$ & $\mathbf{H} / \mathbf{C}$ & $\mathbf{O} / \mathbf{C}$ & $\mathbf{C O O H}$ & $\mathbf{O H}$ & $\mathbf{C}=\mathbf{O}$ \\
\hline 1 & 83.5 & 5.9 & 2.3 & 0.3 & 8.0 & 0.85 & 0.07 & 0.17 & 0.32 & 0.89 \\
\hline 2 & 86.8 & 4.9 & 2.2 & 0.2 & 5.7 & 0.68 & 0.05 & 0.16 & 0.25 & 0.71 \\
\hline 3 & 88.9 & 4.2 & 2.3 & 0.3 & 4.3 & 0.57 & 0.04 & 0.10 & 0.18 & 0.74 \\
\hline 4 & 89.6 & 3.9 & 2.1 & 0.3 & 4.1 & 0.52 & 0.03 & 0.08 & 0.15 & 0.55 \\
\hline
\end{tabular}

The chemical composition of the waste oil is substantially transformed depending on the amount of ozone absorbed. With the increase in the degree of ozonation in the oil content, oxygen content increases as well while carbon, hydrogen and sulfur decreases. The acid number of the oil increases, the viscosity decreases. The optimal degree of ozonation was $11 \mathrm{~g}$ of ozone per $\mathrm{kg}$ of product (Table 3 ).

Table 3. Chemical composition and properties of initial and ozonized oil samples.

\begin{tabular}{|c|c|c|c|c|c|c|c|c|}
\hline \multirow{2}{*}{ Oil sample } & \multicolumn{5}{|c|}{ Content, \% } & \multicolumn{1}{c|}{ Atomic ratio } & $\begin{array}{c}\text { Change in } \\
\text { viscosity, } \\
\text { \% }\end{array}$ \\
\cline { 2 - 9 } & $\mathbf{C}$ & $\mathbf{H}$ & $\mathbf{N}$ & $\mathbf{S}$ & $\mathbf{O}$ & $\mathbf{H} / \mathbf{C}$ & $\mathbf{O} / \mathbf{C}$ & - \\
\hline Without ozonization & 85.4 & 13.3 & 0.2 & 0.3 & 0.8 & 1.9 & 0.01 & -10.5 \\
\hline $\begin{array}{c}\text { With 1-h ozonization } \\
(11 \mathrm{~g} / \mathrm{kg})\end{array}$ & 84.4 & 12.6 & 0.1 & 0.2 & 2.3 & 1.8 & 0.02 & -4.6 \\
\hline $\begin{array}{c}\text { With 1-h ozonization } \\
(22 \mathrm{~g} / \mathrm{kg})\end{array}$ & 83.4 & 11.8 & 0.1 & 0.2 & 4.5 & 1.7 & 0.04 & -4.6 \\
\hline
\end{tabular}

The IR spectroscopy method can be used to identify changes in the fragmented composition of hydrocarbons. In the IR spectra of the ozonized samples, the absorption intensity of aromatic $\mathrm{CH}$ bonds $\left(3040 \mathrm{~cm}^{-1}\right)$ declines; and the proportion of methyl, methylene $\left(2920,1380,720 \mathrm{~cm}^{-1}\right)$, and alicyclic $\left(970 \mathrm{~cm}^{-1}\right)$ fragments increases. We note increased intensity of the absorption bands for oxygen-bearing groups: $\mathrm{O}-\mathrm{H}$ bonds of alcohols and phenols $\left(3400 \mathrm{~cm}^{-1}\right), \mathrm{C}=\mathrm{O}$ bonds of lactones and anhydrides $\left(1770 \mathrm{~cm}^{-1}\right)$, $\mathrm{C}=\mathrm{O}$ bonds of aliphatic $\left(1730 \mathrm{~cm}^{-1}\right)$ and aromatic $\left(1710 \mathrm{~cm}^{-1}\right)$ acids, aromatic ketones $\left(1650 \mathrm{~cm}^{-1}, \mathrm{C}-\mathrm{O}\right.$ bonds of esters, furans, and lactones $\left(1260 \mathrm{~cm}^{-1}\right), \mathrm{S}=\mathrm{O}$ bonds of sulfoxides $\left(1300,1150,1050 \mathrm{~cm}^{-1}\right)$ (fig. 1).

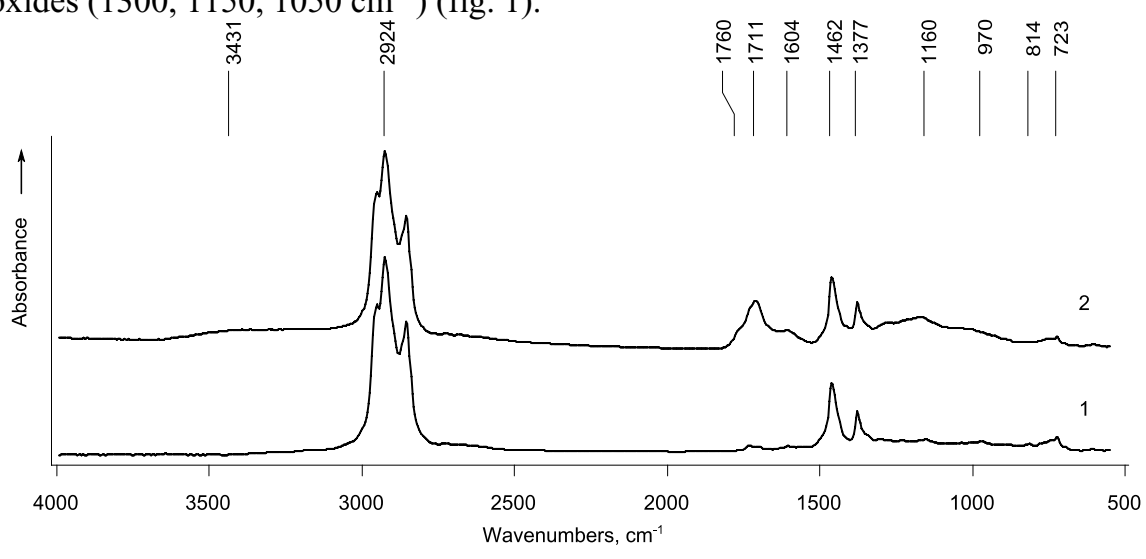

Fig 1. IR spectra of initial (1) and ozonized (2) oil samples.

In the flotation of the coal samples using unmodified spent motor oil, the effectiveness of the process increases with the increase in the metamorphic development of the coal and 
decrease in its oxygen content. In other words, the reagent with non-polar properties has the best adsorption properties with respect to the hydrocarbon fragments of coal with greater metamorphic development (Fig. 2).
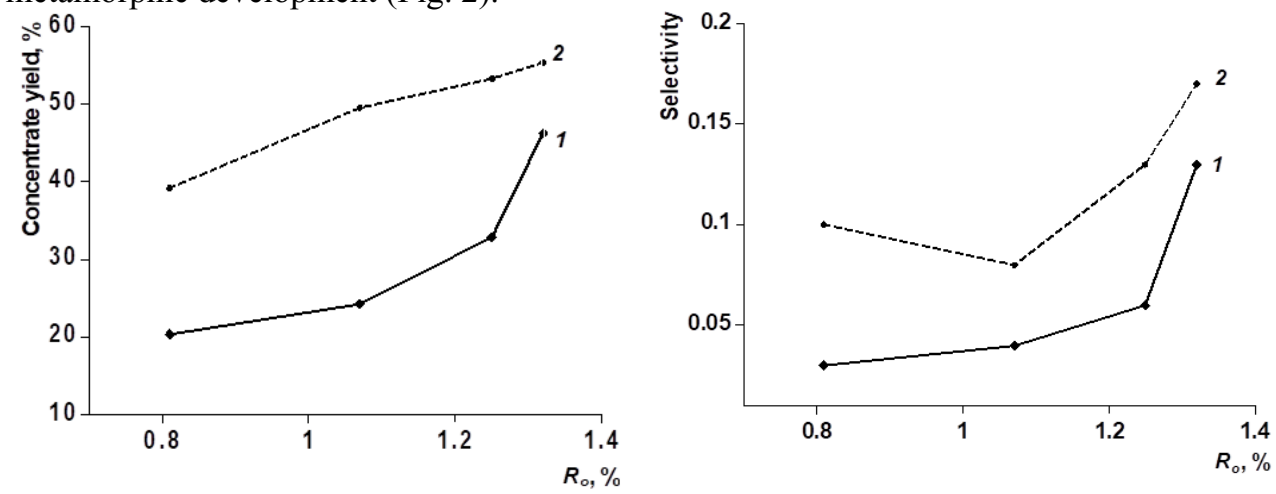

Fig. 2. Results of flotation of coals in different metamorphism stage using initial (1) and ozonized (2) spent oils.

Using ozonized spent oils as flotation agent significantly improves the performance of flotation. Thus bigger effect is observed for low - and average metamorphosed coals (to $R_{o}$ $=1.1 \%)$. The use of ozonized oil significantly changes the flotation outcomes: the concentrate yield increases by a factor between 1.2 (for coal with $R_{\mathrm{o}}=1.32 \%$ ) and 1.9 (for coal with $R_{\mathrm{o}}=0.81 \%$ ), with the decrease in ash content of the concentrate and th increase in ash content of the waste. That corresponds to the increase in the selectivity by factors of 1.1 and 3.3 respectively.

Increased flotation activity of ozonized oil, apparently, contributes to the reduction of viscosity, as well as the appearance of the oil as oxygen-containing and light non-polar compounds. These hydrocarbons can be more easily fixed in the form of a film on the surface of coal particles [3]. At the same time, the positive flotation effect is achieved without the use of additional reagents - modifiers and foaming agents. It can be assumed that the use of analytical processing allows to obtain reagents of complex action with collecting and foaming properties on the basis of spent oils.

The greater flotational activity of the ozonized oil with respect to coal from early metamorphic stages (with $R_{\mathrm{o}}<1.1 \%$ ) may evidently be attributed to greater hydration of the coal particles, because of the presence of hydrophilic carboxyl and hydroxyl groups at their surface. Those groups form hydrogen bonds with the polar groups of the ozonized hydrocarbons in the coal's organic mass. That promotes the adsorption of the reagent.

Coal concentrates obtained by flotation using ozonized oils not only have reduced ash content, but are also enriched with petrographic components of the vitrinite group. Vitrinite has a positive effect on the technological quality of coal: the yield of volatile substances, the heat of combustion and others. The content of mineralized suppressive components of the inertinite group with flotation enrichment of coals of complex petrographic composition decreases.

\section{Conclusion}

Involvement of spent oils in the technology of coal enrichment helps to expand the directions of their utilization and to solve important environmental problems.

The use of ozonolytic modification of spent oils contributes to the production of complex reagents with collecting and foaming properties. High results in the enrichment of 
coals of complex composition are achieved without additional use of modifying and emulsifying additives.

The higher flotation activity of ozonized oils is manifested for low-metamorphosed coals, which associated with the presence of an increased number of hydrophilic oxygencontaining groups on the surface of coal particles.

Improving flotation properties of ozonized spent oils can be called as education in their composition heteropolar compounds, and light non-polar components, which enhance hydrophobicity of the coal particles.

\section{References}

1. A. A. Abramov, Flotation: collecting reagents, in Collection of Research Works vol. 7. (Mountain book, Moscow, 2012) [in Russian]

2. H. Khoshdast, A. Sam, Open Miner. Process. J. 4, 25 (2011)

3. Yu. F. Patrakov, S. A. Semenova, M. S. Klein, T. E. Vahonina, Coal Chem. 4, 22 (2017) [in Russian]

4. S. Dey, Fuel Process. Technol. 94, 151 (2012)

5. J. Soni, S. K. Tripathy, P. K. Banerjee, Int. J. Miner. Process. 134, 97 (2015) 